\title{
$\equiv$

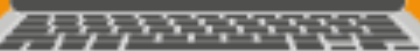 \\ EDUCAÇÃO HÍBRIDA: REGULAMENTAÇÃO PARA A EXPANSÃO NO ENSINO SUPERIOR
}

\author{
Elka Cândida de Oliveira Machado \\ Tribunal de Justiça de Goiás \\ elkamachado2015@gmail.com
}

Eixo 5: Educação híbrida: uma tendência na educação superior

Resumo: Este artigo foi desenvolvido com base nos estudos do Grupo de Estudos e Pesquisas em Tecnologia e Educação a Distância - GeaD/CNPq da Faculdade de Educação da Universidade Federal de Goiás para a compreensão do conceito, formas de organização pedagógica, estrutura, gestão e políticas públicas da Educação a Distância'. Verificar as regulamentações e a expansão da modalidade blended learning no ensino superior constituemse nos objetivos que desencadearam a presente análise bibliográfica. Os resultados indicam que a expansão já instalada assume uma tendência de oferta de cursos dissociados da qualidade.

Palavras-chave: Palavras-chave: Blended Learning. Ensino Superior. Regulamentação.

\section{Introdução}

As céleres transformações advindas da Quarta Revolução Industrial que moldam um domínio tecnológico sobre o mercado de trabalho, os modos de produção e distribuição de mercadorias e, por conseguinte, uma nova organização social (SCHWAB, 2016) indicam a necessidade de uma maior flexibilização da educação de forma a se tornar mais ativa por meio de diversificação e hibridismo (MORAN, 2017). Neste contexto, as tecnologias digitais da informação e comunicação (TDIC) potencializam importantes conexões para as novas exigências educacionais de modalidades de ensino mais dinâmicas como a educação a distância e a educação híbrida - blended learning (VALENTE, 2014).

${ }^{1}$ Este estudo também integra a pesquisa "Políticas de Expansão da Educação a Distância (EaD) no Brasil: Regulação, Qualidade e Inovação em Questão" /CNPq. 


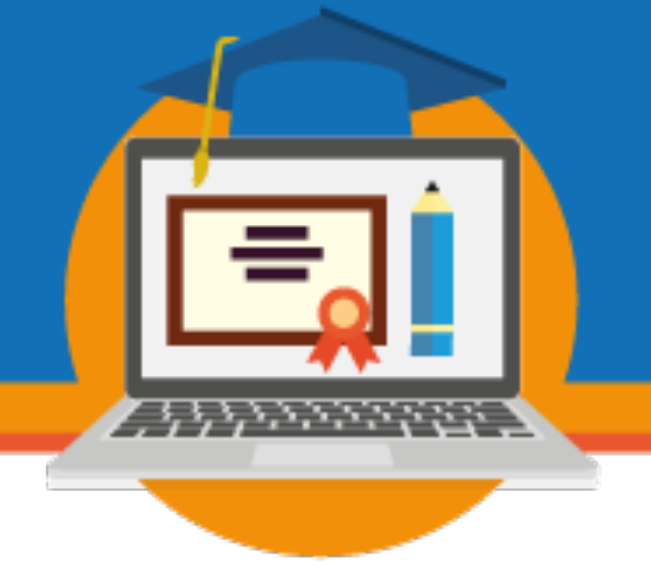

A blended learning posiciona-se como um movimento em expansão numa superação da dicotomia entre os modelos de ensino presencial e a distância que pode ser aferido pela trajetória para a institucionalização da EaD. O ensino superior por ser um dos espaços de produção do conhecimento, inovação e preparação para o trabalho, além de um nicho mercadológico, inserese no inevitável epicentro que acompanha as complexas mudanças.

Este artigo, cunhado em pesquisa bibliográfica, tem por objetivo compreender a evolução conceitual e a tendência de expansão da blended learning no ensino superior.

\section{A trajetória conceitual de blended learning}

O termo blended learning não possui uma definição clara o que permite distintas interpretações (ALTAY e ALTAY, 2019). Híbrido, misturado, mesclado são os significados para blended. Silva, Maciel e Alonso (2017) trazem as distintas denominações para o fenômeno da hibridização na educação: blended learning, b-learning ou ensino híbrido, semipresencial, bimodal ou misto, identificando sua ocorrência

quando o processo de ensino e aprendizagem acontece no ambiente presencial de sala de aula e sua complementação é trabalhada, a distância, por meio de diferentes tecnologias da informação e comunicação. (SILVA, MACIEL e ALONSO, 2017, p. 99).

Friesen (2012) indica que o significado mudou no decorrer do tempo, surgindo com a popularização da internet e World Wide Web (www) no final dos anos de 1990. Uma das primeiras ocorrências do termo blended learning identificadas foi o oferecimento pela companhia EPIC Learning de Atlanta - USA de cursos on-line conjugados à mediação ao vivo, também de forma on-line (FRIESEN, 2012).

As definições mais atualizadas sobre o termo surgiram a partir de 2006, convergindo para a designação da "gama de possibilidades apresentadas pela combinação de Internet e mídia digital com formas de sala de aula estabelecidas que requerem a co-presença física do professor e alunos" (FRIESEN, 2012, p. 1), que tem importância para o contexto do ensino superior.

Bacich e Moran (2015) defendem que o hibridismo é inerente à educação, posto que

\section{SEMINÁRIO DE EDUCAÇÃO A DISTÂNCIA}

Diálogos sobre EaD e uso das TDIC na educação: regulamentação em tempos recentes 


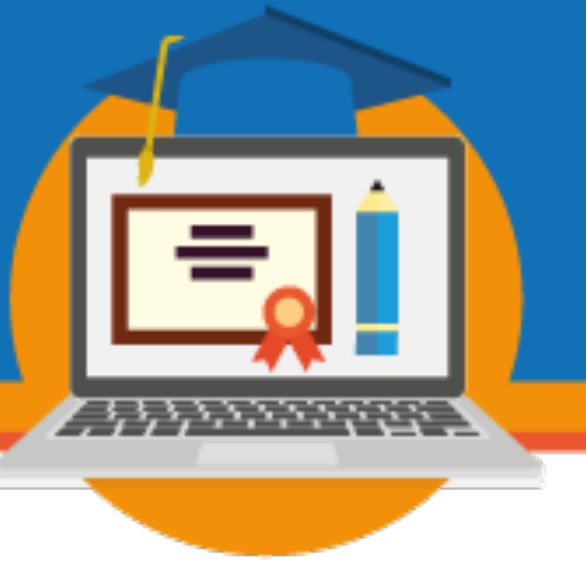

sempre houve conciliação de espaços, públicos e metodologias, todavia, este processo se amplificou pela mobilidade e conectividade em um ambiente mais amplo e profundo. Para eles:

Falar em educação híbrida significa partir do pressuposto de que não há uma única forma de aprender e, por consequência, não há uma única forma de ensinar. Existem diferentes maneiras de aprender e ensinar. $\mathrm{O}$ trabalho colaborativo pode estar aliado ao uso das tecnologias digitais e propiciar momentos de aprendizagem e troca que ultrapassam as barreiras da sala de aula. Aprender com os pares torna-se ainda mais significativo quando há um objetivo comum a ser alcançado pelo grupo (BACICH e MORAN, 2015, p. 45).

Para Valente (2014, p. 79), blended learning se constitui em uma das modalidades de $\mathrm{EaD}$, visto que "com as tecnologias foram criadas diversas modalidades de ensino a distância, inclusive o blended learning, que combina atividades presenciais e atividades educacionais a distância, realizadas por meio das TDIC”. Para este autor, as diversas estratégias para a promoção da aprendizagem ativa tornam-se mais efetivas à medida que as TDIC são utilizadas na educação, integrando as salas de aula de forma a alterar a dinâmica escolar pela organização espaço-temporal e as alterações nas relações interativas entre discentes e entre discentes e docentes (VALENTE, 2014).

\section{Tendências de expansão da blended learning no Brasil}

A tendência de expansão da blended learning está assim, associada à flexibilidade de acesso à aprendizagem pelo aluno por meio da educação à distância e de interação social face a face próprios da sala de aula, bem como a relação custo x benefício das instituições públicas e privadas que permitem a ampliação do público alvo (GRAHAM, 2005).

Segundo Graham (2005), tal tendência conseguia ser visualizada no início do século XXI tanto nos círculos acadêmicos quantos empresariais, com uma previsão de aumento significativo deste modelo nos cursos de ensino superior. No Brasil, a tendência de expansão da blended learning pode ser compreendida pela trajetória para a institucionalização da modalidade de ensino da EaD (SILVA, MACIEL, ALONSO, 2017) cujas bases normativas foram firmadas na década de 1990. Giolo $(2018$, p. 75) identifica iniciativas de criação de 
unidades administrativas como a Subsecretaria de Programas de Educação a Distância, vinculada à Secretaria de Comunicação Social da Presidência da República, em 1995, e a Secretaria de Educação a Distância (SEED), em 1996, subordinada ao Ministério da Educação (MEC) cujas atribuições demonstravam claramente que os objetivos da educação a distância e suas tecnologias "deveriam consistir em programas que auxiliassem na educação brasileira (educação presencial)", sem indicativos, todavia, de uma modalidade autônoma.

A inflexão nos objetivos de subsídios a fim da criação da educação a distância (EaD) como uma segunda modalidade de ensino exsurge a partir da publicação da Lei $\mathrm{n}^{\circ} 9394$ - Lei de Diretrizes e Bases da Educação Nacional, de 20 de dezembro de 1996 (LDB), momento em que a EaD é reconhecida por meio do artigo 80 que estabelece o incentivo pelo Poder Público do desenvolvimento e veiculação de programas de ensino a distância, em todos os níveis e modalidade de ensino, inclusive de educação continuada, com prerrogativas de abertura e regimes especiais e tratamento diferenciado como custos reduzidos e concessão para serviços de radiodifusão sonora e de sons e imagens (GIOLO, 2018). De acordo com Lima e Oliveira (2016, p. 114) este marco legal inclui a "EaD em situação de igualdade com a educação presencial", estabelecendo-se então, uma nítida separação.

Neste processo de institucionalização da EaD (LIMA e OLIVEIRA, 2016), em complemento normativo, foi editado o Decreto $n^{\circ} 2494 / 1998$, alterado pelo Decreto $n^{\circ}$ 2561/1998, que regulamentou o artigo 80 da LDB, definindo que esta forma de ensino teria regime especial, admitida flexibilidade quanto aos horários e carga horária, além da possibilidade de validação entre as instituições credenciadas pelo Poder Público e emissão de certificados com validade nacional. Ademais, a Medida Provisória n ${ }^{\circ}$ 1477/1997, convertida em Lei $n^{\circ}$ 9870/1999, estendeu a atuação na educação superior às pessoas jurídicas sem fins lucrativos, promovendo assim, abertura do mercado para as instituições privadas.

Giolo (2018) indica que, no ano de 2002, existiam milhares de pedidos de credenciamento de instituições e de autorização de cursos na modalidade EaD no MEC diante da abertura à iniciativa privada. A partir da utilização dos dados do Censo da Educação Superior do Instituto Nacional de Estudos e Pesquisas Educacionais Anísio Teixeira (INEP) demonstra 
este autor a vertiginosa expansão da $\mathrm{EaD}$, principalmente pela iniciativa privada que se iniciou a partir de 2002, destinada a segmentos populares, mediante a oferta de cursos baratos, com curtos períodos de duração e baixa qualidade (GIOLO, 2018). Alterações quanto à regulamentação do artigo 80 da LDB ocorrem nos anos de 2005 com o Decreto ${ }^{\circ} 5622$ e 2017 , pelo Decreto $n^{\circ} 9057$. O Decreto $n^{\circ} 5622 / 2005$, definia a EaD como modalidade educacional com a mediação didático-pedagógica nos processos e ensino aprendizagem com a utilização das TDIC. Em 2017, nova regulamentação pelo Decreto n ${ }^{\circ} 9057$ acrescenta as definições dos polos de educação a distância como unidade acadêmica e operacional descentralizada, no País ou no exterior, para o desenvolvimento de atividades presenciais relativas aos cursos ofertados por $\mathrm{EaD}$.

A possibilidade de hibridização nas instituições de ensino superior do sistema federal de ensino manifesta-se pela Portaria $n^{\circ} 2253 / 2001$ do MEC que autoriza a inclusão de disciplinas não presenciais, em seu todo ou em parte, em até $20 \%$ da carga horária do curso. Ademais, tal portaria fixou a faculdade aos alunos em cursar este novo modelo, devendo as instituições manter de forma paralela, o fornecimento de disciplinas no formato presencial, além de ser necessária a práticas dos exames finais também de forma presencial e manutenção da obrigação de cumprimento dos 200 dias letivos fixados pelo artigo 41 da LDB. Batista Júnior (2018, p. 60) aponta que a Portaria $\mathrm{n}^{\circ} 2253 / 2001$ foi formulada pelo MEC para a regulamentação de uma prática em que as instituições “enxergavam no oferecimento de disciplinas e/ou atividades não presenciais, um diferencial para atrair novos alunos, aumentar a receita, sem, contudo, investir muito recurso na estrutura física da instituição", possibilitando o aumento do quantitativo de alunos e, por conseguinte, o lucro.

Procedimentos de credenciamento e recredenciamento de instituições superiores para ensino presenciais e a distância estão regulamentados pela Portaria $n^{0}$ 4361/2004. Em tais regulamentações pode ser notado o "foco voltado para a expansão e regulação, ou seja, a criação de regulamentações que privilegiasse as condições de credenciamento e ampliação da oferta" (LIMA, 2013, p. 115). 


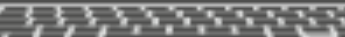

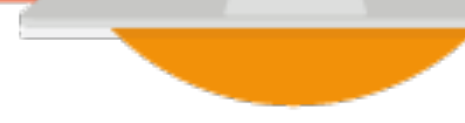

Em 2004, o Ministério de Educação (MEC) aprova a Portaria n 4059 (e revoga a Portaria $n^{\circ} 2253 / 2001$ ) pela qual há autorização para que todos os cursos de graduação de caráter presencial com cursos reconhecidos insiram o ensino à distância em parte de sua carga horária até o patamar de $20 \%$, com a fixação de que as avaliações (e não somente os exames finais como estabelecido na portaria antecessora) ocorram de forma presencial, além de fixar a necessidade de encontros presenciais e atividades de tutoria. Frise-se que por meio desta portaria há uma preocupação quanto à questão da avaliação e da necessidade da mediação por tutores.

A intensificação da expansão na educação híbrida nas instituições de ensino superior está sinalizada em contínuas portarias editadas pelo MEC a partir de 2016 que disciplinam esta matéria. Outra regulamentação acerca da educação híbrida surge neste ano, com a edição da Portaria $n^{\circ} 1134$ que revoga a Portaria nº 4059/2004. Nela, há ampliação de instituições que podem ofertar disciplinas na modalidade a distância como se verifica no artigo $1^{\circ}$. Consta ainda, a previsão da necessidade de profissionais da educação com formação na área do curso e qualificação em nível compatível ao projeto pedagógico para a mediação por tutoria.

Mais uma regulamentação sobre o tema, a Portaria $n^{\circ}$ 1428, é editada em 2018 pelo MEC. Nesta norma, há previsão para a ampliação de $20 \%$ para $40 \%$ da modalidade híbrida para cursos de graduação presencial, excluídos dos cursos de graduação presenciais da área da saúde e de engenharia e, segundo o atendimento dos seguintes requisitos do artigo $3^{\circ}$ :

I - a IES deve estar credenciada em ambas as modalidades, presencial e a distância, com Conceito Institucional - CI igual ou superior a 4 (quatro); II - a IES deve possuir um curso de graduação na modalidade a distância, com Conceito de Curso - CC igual ou superior a 4 (quatro), que tenha a mesma denominação e grau de um dos cursos de graduação presencial reconhecidos e ofertados pela IES; III os cursos de graduação presencial que poderão utilizar os limites definidos no caput devem ser reconhecidos, com Conceito de Curso - CC igual ou superior a 4 (quatro); e IV - A IES não pode estar submetida a processo de supervisão, nos termos do Decreto ${ }^{\circ} 9.235$, de 2017, e da Portaria Normativa MEC n ${ }^{\circ} 315$, de 4 de abril de 2018.

A Portaria $n^{\circ}$ 1428/2018 apresenta a possibilidade de atuação tanto de tutores quanto profissionais da educação com formação na área do curso e qualificados em nível compatível ao previsto no projeto pedagógico do curso (PPC).

\section{SEMINÁRIO DE EDUCAÇÃO A DISTÂNCIA}

Diálogos sobre EaD e uso das TDIC na educação: regulamentação em tempos recentes 3 a 6 de novembro de 2020 - Brasília/DF - Online 


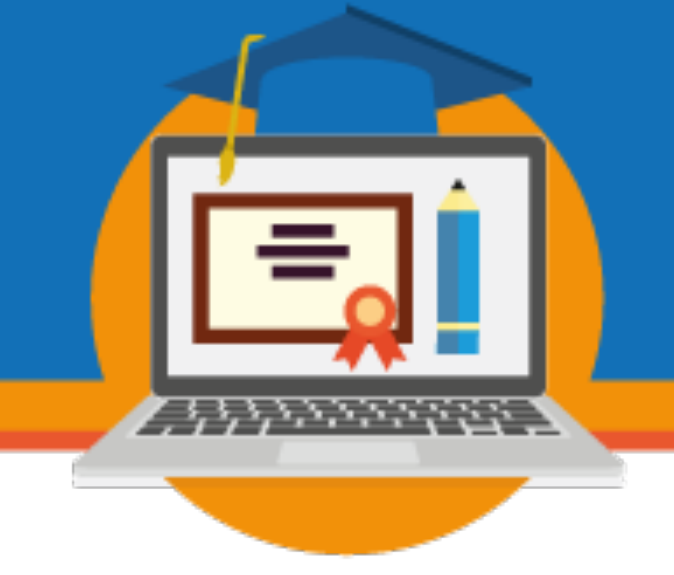

Mas a expansão do ensino híbrido no ensino superior avança rapidamente por meio de regulamentações pelo MEC. Em 6 de dezembro de 2019, adveio a Portaria n 2117 que mais uma vez amplia o oferecimento de curso por meio do blended learning, de forma generalizada para os cursos, salvo o de medicina. Para a oferta da carga horária de até $40 \%$ está sujeita à obtenção, pelo curso, de conceito igual ou superior a três na metodologia, atividades de tutoria, ambiente virtual de aprendizagem (AVA) e nas tecnologias de informação e comunicação (TIC). Tal redução no critério quanto ao conceito obtida pelo curso também se traduz em uma estratégia de maior expansão da educação híbrida, principalmente nas instituições privadas.

Outro ponto de destaque pode ser observado na omissão quanto à atuação dos profissionais da educação na atividade de mediação, acenando para a diminuição de custos com a força de trabalho nos cursos.

Tais regulamentações compõem o arcabouço normativo que oficializam assim, o sistema híbrido nas instituições de ensino superior, flexibilizando, a dicotomia entre EaD e modalidade presencial, num nítido esforço de expansão.

\section{Considerações Finais}

A análise das regulamentações brasileiras acerca do ensino superior revela uma expansão contínua da educação híbrida. Uma tendência de expansão que surgiu no início deste século com a Portaria $\mathrm{n}^{\circ} 2253 / 2001$, mas que se apresenta atualmente como uma realidade nas instituições superiores. A análise das recentes portarias do MEC demonstra que tal expansão ocorre em distintas frentes, em especial, a Portaria $n^{\circ}$ 2117/2019: a) atingindo uma maior quantidade de cursos, à exceção do curso de medicina; b) diminuindo os patamares de qualidade pela diminuição dos conceitos obtidos por estes cursos; c) omitindo sobre a necessidade de qualificação do trabalho por profissionais da educação na mediação destes cursos.

Tais frentes indicam que a expansão já instalada assume uma tendência de oferta de cursos dissociados da qualidade.

\section{SEMINÁRIO DE EDUCAÇÃO A DISTÂNCIA}




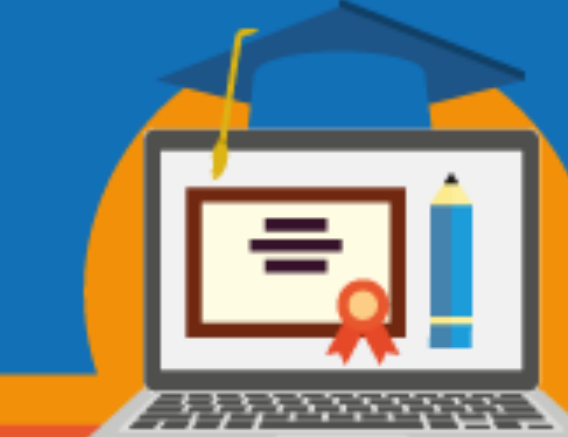

\section{Referências}

ALTAY. Firat Ismail; ALTAY, Ayse. A review of studies on blended learning in EFL Enviromente. Internacional Journal of Curriculum and Instruction. v. 11, n. 1, p. 125-140, 2019. Disponível em: https://eric.ed.gov/?id=EJ1217924. Acesso em 07 jan. 2020.

BACICH, Lilian; MORAN José. Aprender e ensinar com foco na educação híbrida. Revista Pátio, $\mathrm{n}^{\mathrm{o}}$ 25, junho, 2015, p. 45-47. Disponível em: http://www.grupoa.com.br/revistapatio/artigo/11551/aprender-e-ensinar-com-foco-naeducacao-hibrida.aspx. Acesso em 02 jan. 2020.

BATISTA JÚNIOR, Roberto Oliveira. Ensino Híbrido: um estudo sobre a inserção de até $20 \%$ de Ead na carga horária de cursos presenciais da UFPE. Pernambuco. 176 p. Dissertação ( Mestrado) - Programa de Pós-Graduação em Educação Matemática e Tecnológica da Universidade Federal de Pernambuco, 2018. Disponível em: https://repositorio.ufpe.br/bitstream/123456789/30888/1/DISSERTA\%C3\%87\%C3\%830\%2 0Roberto\%20Oliveira\%20Batista\%20J\%C3\%BAnior.pdf. Acesso em 06 jan. 2020.

BRASIL. Medida Provisória n ${ }^{\circ}$ 1.477-39/ 1997. Dispõe sobre o valor total anual das mensalidades escolares e dá outras providências. Brasília, DF, ago 1997. 


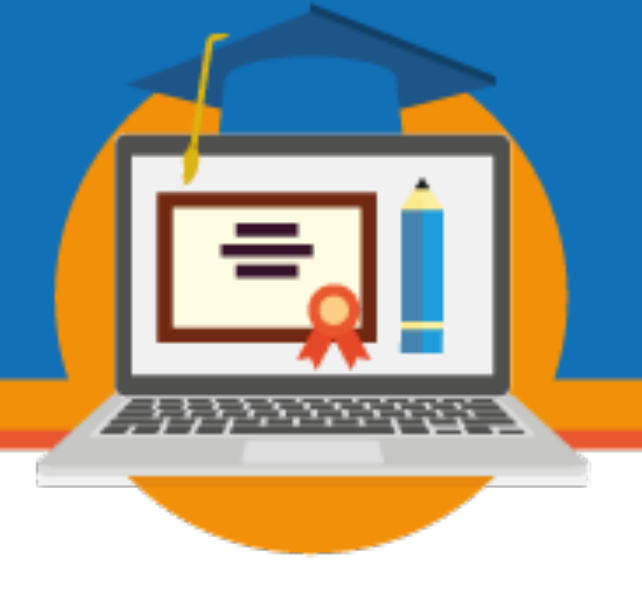

BRASIL. Decreto ${ }^{\circ}$ 2.494/98, de 10 de fevereiro de 1998. Disponível em: http://portal.mec.gov.br/sesu/arquivos/pdf/dec 2494.pdf. Acesso em: 07 jan. 2020.

BRASIL. Decreto n ${ }^{\circ} 2.561$, de 27 de abril de 1998. Altera a redação dos arts. 11 e 12 do Decreto n. ${ }^{\circ}$ 2.494, de 10 de fevereiro de 1998, que regulamenta o disposto no art. 80 da Lei n. ${ }^{\circ}$ 9.394, de 20 de dezembro de 1996. Brasília, DF, abr. 1998

BRASIL. Lei n. 9.394, de 20 de dezembro de 1996. Estabelece as diretrizes e bases da educação nacional. Diário Oficial [da] República Federativa do Brasil, Brasília DF, 23 dez. 1999. Disponível em: http://www.planalto.gov.br/ccivil_03/Leis/L9394.htm . Acesso em:10 jan. 2020 .

BRASIL. Ministério da Educação. Portaria ${ }^{\circ}$ 2253, de 18 de outubro de 2001. Em: https://www2.camara.leg.br/legin/marg/portar/2001/portaria-2253-18-outubro-2001-412758norma-me.html. Acesso em 06 jan. 2020.

BRASIL. Ministério da Educação. Portaria $n^{\circ} 4059$, de 10 de dezembro de 2004. Em: http://portal.mec.gov.br/sesu/arquivos/pdf/nova/acs portaria4059.pdf. Acesso em 06 jan. 2020.

BRASIL. Ministério da Educação. Portaria n 1134, de 10 de outubro de 2016. Disponível em: https://abmes.org.br/legislacoes/detalhe/1988/portaria-n-1134 . Acesso em: 06 jan. 2020.

BRASIL. Ministério da Educação. Portaria n 1428, de 28 de dezembro de 2018. Disponível em:https://abmes.org.br/legislacoes/detalhe/2669/portaria-mec-n-1.428-2018. Acesso em: 06 jan. 2020. 


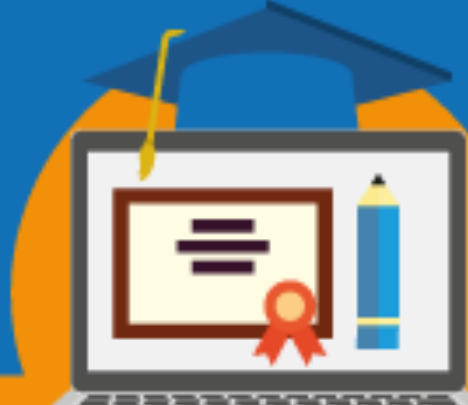

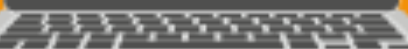

BRASIL. Ministério da Educação. Portaria n ${ }^{\circ}$ 2117, de 06 de dezembro de 2019. Disponível em:https://abmes.org.br/arquivos/legislacoes/Portaria-mec-2117-2019-12-06.pdf Acesso em: 06 jan. 2020.

FRIESEN, Norm. Report: defining blended learning. 2012. Disponível em: https://www.normfriesen.info/papers/Defining Blended Learning NF.pdf Acesso em: 07 jan. 2020.

GRAHAM, Charles R. Blended learning systems: definitions, current trends and future directions. In: BONK, C. J. \& GRAHAM, C. R. (Org.) Handbook of blended learning: Global Perspectives, local designs. San Francisco, CA: Pfeiffer Publishing, pp. 3-21, 2004.

LIMA, Daniela da Costa Britto Pereira. Políticas públicas de EaD no ensino superior: uma análise a partir das capacidades do estado. Rio de Janeiro: Universidade Federal do Rio de Janeiro, 2013. 286 p. Tese (Doutorado em Ciências, em Políticas Públicas, Estratégias e Desenvolvimento) - Programa de Pós-Graduação em Políticas Públicas, Estratégias e Desenvolvimento, Instituto de Economia, Universidade Federal do Rio de Janeiro, Rio de Janeiro, 2013.

LIMA. Daniela da Costa Britto Pereira Lima; OLIVEIRA. João Ferreira. Institucionalização da EaD pública no Brasil: limites e potencialidades do processo. In VALDEZ, Diane; ASSIS Lúcia Maria (Org). Políticas e história da educação. Campinas: Mercado das Letras, p. 111-134, 2016.

MORAN, José. A EAD no Brasil: cenário atual e caminhos viáveis de mudança. In Educação a Distância: pontos e contrapontos. Disponível em: http://www2.eca.usp.br/moran/wpcontent/uploads/2013/12/cenario.pdf. Acesso em: 07 jan. 2020. Acesso em: 05 jan. 2020. 


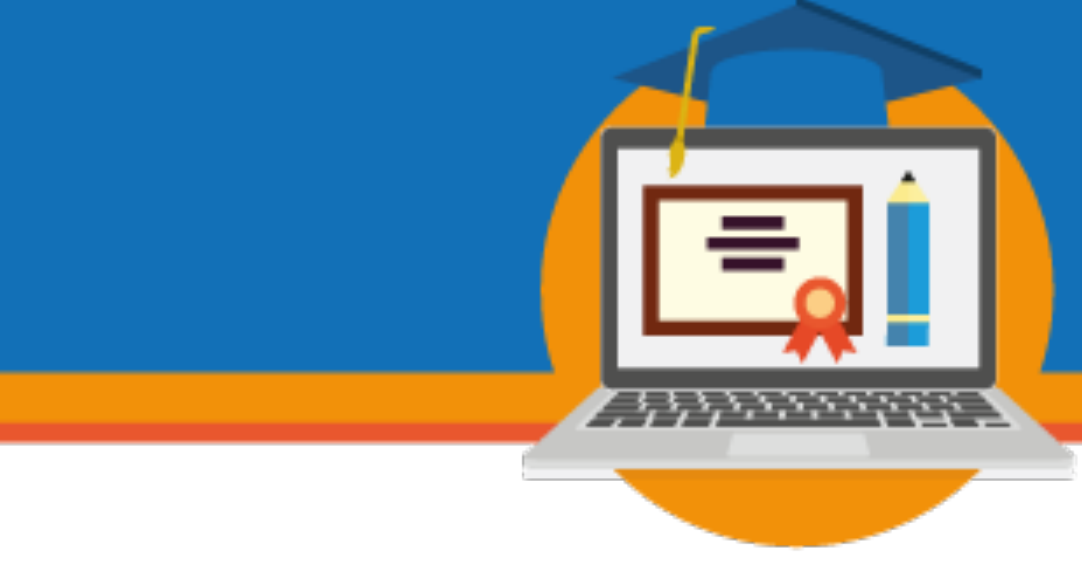

MORAN, José. Metodologias ativas e modelos híbridos na educação. In Solange e outros (Orgs). Novas Tecnologias Digitais: Reflexões sobre mediação, aprendizagem e desenvolvimento. Curitiba: CRV, 2017, p.23-35

SCHWAB, Klaus. A quarta revolução industrial. São Paulo: Edipro, 2016.

SILVA, Michele Rejane Coura da; MACIEL, Cristiano; ALONSO, Kátia Morosov. Hibridização do ensino nos cursos de graduação presenciais das universidades federais: uma análise da regulamentação. Revista Brasileira de Política e Administração da Educação Periódico científico editado pela ANPAE, [S.1.], v. 33, n. 1, p. 95 - 117, abr. 2017. ISSN 24474193. Disponível em: https://seer.ufrgs.br/rbpae/article/view/74042. Acesso em: 11 jan. 2020. doi:https://doi.org/10.21573/vol33n12017.74042.

VALENTE. José Armando. Blended learning e as mudanças no ensino superior: a proposta da sala de aula invertida. Educar em Revista, v. 4, p. 79-97, 2014. Disponível em: http://www.scielo.br/scielo.php?script=sci abstract\&pid=S010440602014000800079\&lng=en\&nrm=iso\&tlng=pt. Acesso em 07 jan. 2020. 